\title{
GCU
}

Glasgow Caledonian

University

University for the Common Good

\section{Impacts of high penetration level of fully electric vehicles charging loads on the thermal ageing of power transformers}

Qian, Kejun; Zhou, Chengke; Yuan, Yue

Published in:

International Journal of Electrical Power and Energy Systems

DOI:

10.1016/j.ijepes.2014.09.040

Publication date:

2015

Document Version

Author accepted manuscript

Link to publication in ResearchOnline

Citation for published version (Harvard):

Qian, K, Zhou, C \& Yuan, Y 2015, 'Impacts of high penetration level of fully electric vehicles charging loads on the thermal ageing of power transformers', International Journal of Electrical Power and Energy Systems, vol. 65, pp. 102-112. https://doi.org/10.1016/j.ijepes.2014.09.040

\section{General rights}

Copyright and moral rights for the publications made accessible in the public portal are retained by the authors and/or other copyright owners and it is a condition of accessing publications that users recognise and abide by the legal requirements associated with these rights.

Take down policy

If you believe that this document breaches copyright please view our takedown policy at https://edshare.gcu.ac.uk/id/eprint/5179 for details of how to contact us. 


\title{
Impacts of High Penetration Level of Fully Electric Vehicles Charging Loads on the Thermal Ageing of Power Transformers
}

\author{
Kejun Qian, Jiaqing Zhao, Chengke Zhou, S.Member, IEEE, FIET, Yue Yuan, Member, IEEE
}

\begin{abstract}
This paper develops a methodology to determine the impacts of high penetration level of fully electric vehicles (FEVs) charging loads on the thermal ageing of power distribution transformers. The method proposed in this paper is stochastically formulated by modelling the transformer life consumption due to FEVs charging loads as a function of ambient temperature, start time of FEVs charging, initial state-of-charge and charging modes. FEVs loads are modelled using the results from an analytical solution that predicts a cluster of FEVs chargers. A UK generic LV distribution network model and real load demand data are used to simulate FEVs' impacts on the thermal ageing of LV power distribution transformers. Results show that the ambient temperature, FEVs penetration level, and start time of charging are the main factors that affect the transformer life expectancy. It was concluded that the smart charging scenario generally shows the best outcome from the loss of life reduction perspective. Meanwhile, public charging which shifts a large percentage of charging load to commercial and industrial areas can significantly alleviate the residential transformer loading thus has little impact on the loss of life of transformers. The proposed method in this paper can be easily applied to the determination of the optimum charging time as a function of existing loads, and ambient temperature.
\end{abstract}

Index Terms-- full electric vehicles (FEVs), electricity distribution systems, power distribution transformers, thermal ageing

\section{INTRODUCTION}

$\mathrm{F}$ ULLY Electric Vehicles (FEVs) hold the promise, if widely adopted, of drastically reducing carbon emissions from surface transport and could, therefore, form a major thrust in the global efforts to meet the emissions reduction targets. In order to make a significant impact on $\mathrm{CO}_{2}$, FEVs must become a mainstream option for the majority of motoring public. Otherwise, their impacts will be limited and the ability to achieve the global $\mathrm{CO}_{2}$ emission reduction targets will severely be compromised.

With increasing number of FEV connected to power systems for charging, there is a concern that existing

Kejun Qian and Jiaqing Zhao are with the Suzhou Power Supply Company, State Grid Corporation of China, Suzhou, 215004, China. (email: kejun.qian@ hotmail.com).

Chengke Zhou is with the School of Engineering and Built Environment, Glasgow Caledonian University, Glasgow G4 0BA, U.K. (e-mail: c.zhou@gcu.ac.uk).

Yue Yuan is with the College of Energy and Electrical Engineering, Hohai University, Nanjing 210098, China. distribution networks may become more heavily loaded than anticipated when they were designed. Low level of penetrations may result in little impact but, as the numbers increase, there could be a real possibility of local distribution networks being overwhelmed. Various studies have been carried out to evaluate whether the existing electricity network and generation capacity could accept the widespread adoption of FEVs [1-4]. These studies concluded that existing/planned generation capacities are sufficient to meet the additional demand according to the modelled penetration level of FEVs and also highlighted that FEVs pose little impact to the existing electricity network if proper load management strategies can be put in place. However, this may not be the case in local distribution systems in the UK, where ageing and overloading of distribution plants have already become a significant problem, as most of the distribution transformers and cables were installed between 1950s and 1960s [5].

Distribution systems are designed to deliver electricity to the final customers and their sizing is usually based on an estimated electricity demand. As FEVs still represent a small niche market hardly exceeding $1 \%$ of the passenger car market today, the Distribution Network Operators (DNOs) have very limited experience or knowledge of managing high penetration of FEVs charging loads. Therefore, there is a general need to develop modelling techniques to help quantify the effects that high penetration level of FEV charging loads may have on distribution networks and thus ensure that this environmentally benign technology is not unnecessarily constrained. Power transformers are vital links in distribution systems which are sen-to experience unprecedented loads from FEV charging. Furthermore, transformers in their present form will likely continue to be in service in power systems for many decades to come due to its widespread use and inherent high reliability in its simplicity. Therefore, the impacts of typical smart grid operations such as FEV charging activities must be assessed accurately for transformer health and performance considerations.

The present authors [6] have developed detailed models of FEV battery charging loads by taking into account the probability in battery state-of-charge (SOC) and start time. Detailed analysis was presented in [6] regarding the FEVs charging loads on distribution networks, however, the effects of FEVs charging loads on distribution plants such as 
transformers and cables were not taken into account. Staats $e t$ al. [7-8] and Orr et al. [9] developed statistical models for predicting the effect that widespread FEVs battery charging will have on distribution system net harmonic currents and harmonic voltage levels, respectively. Again, the work presented in [7-9] focused on the overall distribution system, rather than on the individual distribution plants. Gómez et al. [10] developed a program to assess transformer life consumption due to additional FEV charging loads in distribution systems by modelling the transformer life as a function of the battery characteristics and charging algorithm. The work reported in [10] highlighted the relationship between the transformer life consumption and the total harmonic distortion (THD) of the battery charger current. However, the battery charging load, which is the key of the modelling was oversimplified by assuming all FEVs have the same charging start time and the same charging duration.

This paper presents a methodology to evaluate the effect of FEVs charging loads on the thermal ageing of power distribution transformer. The method accounts for the probabilities of FEVs battery charging loads, i.e., the randomness of individual charger start-time, initial batterystate-of charge (SOC), and charging modes.

\section{Mathematical Modelling}

\section{A. Modelling of electric vehicle charging loads}

FEVs are additions to existing load. They are distinctly different from other electrical loads due to their nature in high mobility and unpredictability. There are mainly three key factors which may influence the effect of FEVs on distribution networks, namely the charging characteristics of the electric vehicles, FEVs user profile and FEVs battery charger.

\section{- Fully electric vehicles}

FEVs penetration level There are many opinions regarding the future take-up of FEVs. This is an issue which is very difficult to predict, as considerable uncertainties surround the degree to which FEVs will penetrate the transport sector. The potential number of FEVs on UK roads is predicted to be one million by 2020 . One study in 2010 forecasted that FEVs will overtake hybrid vehicles in UK market share and will reach a combined total over $20 \%$ by 2020 [11].

It is clear, however, that irrespective of the percentage penetration level of the FEVs market, electric utilities must be prepared to accept this load. In this paper, the FEVs penetration level will be assumed to increase from $0 \%$ (base case) to a maximum value for case studies. As a starting point, we will look at $1 \%$ of penetration, a figure for the near term, which could be achieved within the next five years. In the UK, this translates to $284,000 \mathrm{FEVs}$ (there are approximately 28.4 million cars registered in the UK by the end of 2010 [12]). It is assumed that the number of registered vehicles in the UK will remain fairly constant over the studied period of time.

Battery types Lead acid, nickel metal hydride (NiMH) and lithium-ion are the three main types of batteries for electric vehicles. Recently, FEVs are becoming increasingly attractive with the advancement of lithium-ion battery technology which has higher power and energy density. Due to the fact that lithium-ion batteries dominate the most recent group of FEVs in development, it is assumed in this paper that the studied FEVs employ lithium-ion batteries. A generic charging characteristic for lithium-ion battery will be outlined in the Section of "FEVs battery charger and charging profile."

\section{- FEVs user profile}

Since not all FEVs start charging simultaneously, it is assumed in this paper that, the time of switching on an individual charger is a random variable, with a probability density function (pdf) $f(t)$, which is determined by the electricity tariff, the pattern of vehicle traffic and the charging characteristics. The initial state-of-charge (SOC) of the FEV battery before recharging (i.e., residual capacity since last charge) is also assumed to be a random function of the total distance it travels since it was last charged. The initial $\mathrm{SOC}_{2} E_{\mathrm{i}}$ can be assumed therefore as a probability density function of $h(E)$, where $E$ is the SOC, which varies from zero to the full capacity of the battery.

Initial state-of-charge before recharging In order to determine the variation of FEVs battery charging power demand with time during a recharge cycle, a statistical distribution of the initial state-of-charge before recharging is needed. This is because the FEVs charging curve depends on the initial state-of-charge before recharging.

According to the general information available on personal automobile travel [13], for private cars, the daily travel distance subjects to a normal distribution with a mean of 22.3 miles and a standard deviation of 12.2 miles.

Given the average daily travel distance, the SOC at the beginning of a recharge cycle (residual battery capacity) can be estimated using Equation (1), assuming that the SOC of a FEV drops linearly with the distance of travel.

$$
E_{i}=\left(1-\frac{\alpha^{*} d}{d_{R}}\right) * 100 \%
$$

where $E_{i}$ represents the initial SOC of an FEV battery, $d$ is the daily distance travelled by a car, which is a random variable, $\alpha$ is the number of days the FEV has travelled since last charge, $d_{R}$ is the maximum range of the FEV. A typical value for $d_{R}$ is 100 miles [14]. Assuming all private FEVs are recharged once every two days and that recharge is carried to completion. The probability density function $h$ for the initial battery SOC is given by Equation (2), which is derived from Equation (1) and the distribution of daily travel distance obtained from [13].

$$
h(E ; \mu, \sigma)=\frac{1}{\frac{d_{R}}{\alpha}(1-E) \sqrt{2 \pi \sigma^{2}}} e^{-\frac{\left[\ln (1-E)-\left(\mu-\ln \frac{d_{R}}{\alpha}\right)\right]^{2}}{2 \sigma^{2}}}, 0<E<1^{(2)}
$$

This model has taken into account the effect of the interval in number of days between recharge of a FEV battery on the initial SOC. The initial SOC has a mean $44 \%$ after two days' travel for private FEVs.

Start time of battery recharging The start time of battery charging, determined by the purpose of the use of the FEVs 
and by the electricity tariff rate structure, has an element of randomness.

It is assumed in this paper that private FEVs are mainly for commuting purpose and the distribution of FEVs trips (shown in percentage of daily traffic versus time of day) complies with the figure shown in Figure 1. It can be observed that there are two peaks for weekdays, the morning peak (8.00am-09.00am) and the evening peak $(5.00 \mathrm{pm}-6.00 \mathrm{pm})$, while there is one peak (12.00am-1pm) for weekends [15].

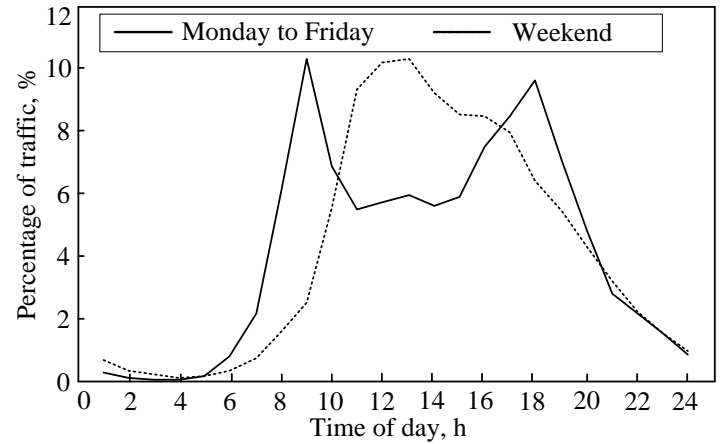

Fig. 1 Trips in progress by time of day and day of week

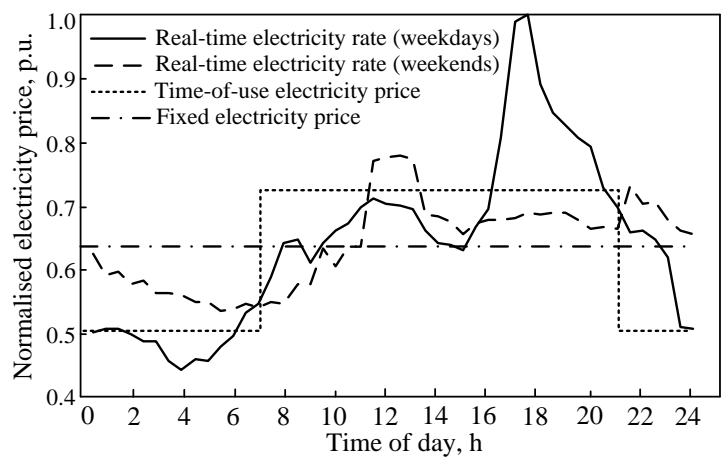

Fig. 2 Electricity tariff structure

The FEV load demand can be dictated to some extent by the electricity tariff structure. In this paper, three types of typical electricity tariff structures are given consideration: fixed electricity rate, time-of-use electricity rate, and real-time electricity rate. The fixed electricity rate refers to the tariff in which energy charge per $\mathrm{kWh}$ remains constant regardless of the time of use. Time-of-use electricity price divides the tariff into two main blocks: off-peak and on-peak price [16]. The real-time price, i.e. the electricity rate per $\mathrm{kWh}$ varies by time of day and month of year [17-18], as shown in Figure 3, is based on the wholesale price in the UK [19]. These ignore any capital recovery or standing charge element to the tariff structure. Figures 1 and 2 will be used to determine the percentage of FEVs to be charged at each time instant.

To account for the future changes to the electricity tariff and regulation of FEV charging loads, four FEV charging scenarios have been developed in this paper, comprising uncontrolled domestic charging, uncontrolled domestic offpeak charging, smart domestic charging, and uncontrolled public charging. Among the four scenarios, uncontrolled domestic charging represents the 'worst case', where all FEVs start charging when drivers arrive home at the peak load time. Uncontrolled domestic off-peak charging reflects the effect of price incentives on the charging of FEVs. Smart charging represents a future charging scenario where smart metering and advanced communication techniques are widely used in FEV battery charging systems. Uncontrolled public charging is a more realistic charging scenario where FEV owners are able to charge at both the workplace and at home.

\section{- FEVs battery charger and charging profile}

Most electric cars used conductive coupling to supply electricity for recharging after the California Air Resources Board settled on the $S A E$ J1772-2001 standard. In Europe, the IEC 61851-1 charging modes are used to classify charging equipment. The charging modes for conductive charging of electric vehicles include Mode 1, Mode 2, Mode 3 and Mode 4, shown as below in Table I.

TABLE I

THE STANDARD CHARGING MODES DEFINED IN IEC 61851-1 [20]

\begin{tabular}{cccc}
\hline \hline Mode & Phase & Maximum current & Maximum voltage \\
\hline \multirow{2}{*}{ Mode 1 (AC) } & 1 & $16 \mathrm{~A}$ & $250 \mathrm{~V}$ \\
\cline { 2 - 4 } & 3 & $16 \mathrm{~A}$ & $480 \mathrm{~V}$ \\
\hline \multirow{2}{*}{ Mode2 (AC) } & 1 & $32 \mathrm{~A}$ & $250 \mathrm{~V}$ \\
\cline { 2 - 4 } & 3 & $32 \mathrm{~A}$ & $480 \mathrm{~V}$ \\
\hline \multirow{2}{*}{ Mode 3 (AC) } & 1 & $32 \mathrm{~A}$ & $250 \mathrm{~V}$ \\
\cline { 2 - 4 } & 3 & $250 \mathrm{~A}$ & $690 \mathrm{~V}$ \\
\hline Mode 4 (DC) & & $400 \mathrm{~A}$ & $600 \mathrm{~V}$ \\
\hline \hline
\end{tabular}

For UK residential customers, due to the $60 \mathrm{~A}$ maximum fuse that is typically installed in UK households [21], the most likely level of charger belongs to Modes 1 and 2. Most people do not usually require fast recharging because they have enough time, six to eight hours (depending on charge level) during the work day or overnight at home to recharge, in order to avoid the inconvenience of visiting a public charging station. In addition, fast charging can result in Lithium plating of the anode due to the inability of the intercalation layers to accommodate the Lithium ions quickly enough, consequently shortens battery cycle life. In this paper, it is assumed that those FEVs charging at home employ Modes 1 and 2 to recharge their batteries, while those charging at public charging stations employ Modes 3 and 4 (fast charging).

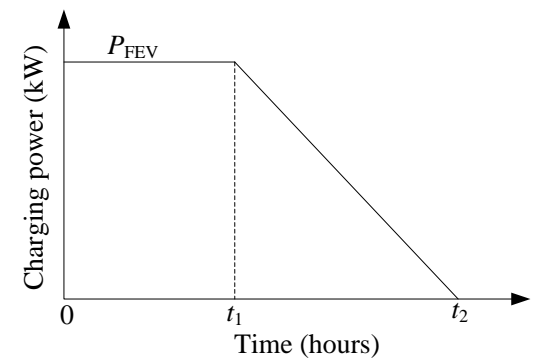

Figure 3 Typical active charging power of FEV charger

Charging profiles for FEVs can vary depending on several parameters: battery type, charging mode (level) and the electricity supply network. As above mentioned, this paper assumes that FEVs batteries are based on lithium-ion battery technology. The main focus here is on the power demand for charging FEV batteries. We adopt a generic model of FEV battery charging profiles based on actual data and simplify it by linearising piecewise the charging profile. The charging 
profile is displayed in Figure 3, according to [3], [7], [10] and [22].

It can be seen from Figure 3 that when the battery state-ofcharge is low, the charger operates at rated current, which enables a large percentage of the battery charge being restored during the first charging hours. This continues until the battery voltage reaches its gassing limit, at which time current drops as the charger maintains a constant voltage. The model profile can be mathematically expressed as,

$$
P(t)= \begin{cases}P_{F E V} & 0<t<t_{1} \\ P_{F E V} \frac{\left(t_{2}-t\right)}{\left(t_{2}-t_{1}\right)} & t_{1}<t<t_{2}\end{cases}
$$

where $P(t)$ is the charging power in $\mathrm{kW}, P_{F E V}$ is the rated charging power in $\mathrm{kW}$, which varies depending on the charging mode. $P_{F E V}=3.5 \mathrm{~kW}$ is assigned for charging Mode 1 , as the maximum domestic socket in Europe is $3.5 \mathrm{~kW}$. Mode 1 is assumed to fully recharge a FEV battery within eight hours. $P_{F E V}=6.6 \mathrm{~kW}$ is assigned for charging Mode 2, as this is the usual value for commercial FEVs up to date. Mode 2 is assumed to be a double speed charger compared to Mode 1, i.e., it aims to complete recharge in four hours. $P_{F E V}=40 \mathrm{~kW}$ is assigned for charging Modes 3 and 4, in order to achieve the fast charging target that a $25 \mathrm{kWh}$ battery pack can be charged to $80 \%$ capacity in about 30 minutes. $t_{1}$ and $t_{2}$ are time instants that determine the variations in charging power magnitude. Values of $t_{1}$ and $t_{2}$ are listed in Section 4.B.

In practice, the exact charging characteristics of a lithiumion battery, even under simplified conditions, is a complex function of numerous interdependent phenomena of battery state of charge (SOC), ambient temperature and charger type. In this paper, the effect of ambient temperature on the FEV battery charging characteristics is not taken into account. With respect to the effect of SOC on the charging profile, it is reasonable to expect that for a partially charged/discharged battery, charger power follows a time-shifted original power curve. In other words, the charger begins charging at a point indicative of its initial SOC so that the area under the charging power curve to the right of the starting point equals the energy required by the battery.

\section{B. Impact of electric vehicle charging loads on transformer thermal ageing}

This part aims to determine the mathematical relationship between transformer thermal ageing and FEVs charging loads.

Three mechanisms contribute to the insulation ageing or deterioration in transformers: hydrolysis, oxidation and pyrolysis. Therefore, insulation ageing or deterioration is a time function of temperature, moisture content, and oxygen content. The moisture and oxygen can be controlled by modern oil preservation systems, leaving insulation temperature as the controlling parameter. Since the temperature distribution in most transformers is not uniform, the part operating at the highest temperature will undergo the greatest deterioration. Therefore, in ageing studies it is usual to consider the ageing effects produced by the highest (hot-spot) temperature.
Due to the fact that transformers are mainly loaded with different current and at different ambient temperature, the hotspot temperature is not constant and there is a strong practical interest for the functional dependence of ageing from the hotspot temperature.

A method for determining the equivalent transformer life (in hours and days) at the reference temperature that will be consumed in a given time period is presented in the IEEE Std C57.91-1995 [23]. In order to account for the variations in both ambient temperature and load demand levels, it is necessary to discretise the load profile with time intervals $\Delta t$ for the 24-hour period. According to [23], the equivalent ageing factor for a time period of interest can be expressed as,

$$
F_{E Q A}=\frac{\sum_{n=1}^{N} F_{A A, n} \Delta t_{n}}{\sum_{n=1}^{N} \Delta t_{n}}
$$

where $F_{E Q A}$ is the equivalent ageing factor for the time period of interest, $n$ is the index of time interval. $N$ is the total number of time intervals, which is taken as 48 for the number of halfhourly time intervals in a day. $\Delta t$ is the time interval, $\Delta t_{\mathrm{n}}=30$ mins, and $F_{\mathrm{AA}, \mathrm{n}}$ is the ageing acceleration factor for the temperature which exists during the time interval $\Delta t_{\mathrm{n}} . F_{\mathrm{AA}, \mathrm{n}}$ can be expressed in Equation (5),

$$
F_{A A, n}=\exp \left(\frac{15000}{383}-\frac{15000}{\Theta_{H, n}+273}\right)
$$

where $\Theta_{H, n}$ is the winding hot-spot temperature during the time interval $\Delta t_{\mathrm{n}}$ in degree Celsius. Therefore, the per cent loss of transformer life due to the presence of FEVs charging loads can be expressed as below,

$$
\Delta L=\frac{\left(F_{E Q A-E V}-F_{E Q A-N E V}\right) \times t}{L_{N}} \times 100 \%
$$

where $\Delta L$ is per cent loss of transformer life due to the presence of FEVs charging loads, $F_{E Q A-E V}$ and $F_{E Q A-N E V}$ are the equivalent ageing factors with and without presence of the FEVs charging loads, respectively, for the total time period $t$ in hours, $L_{\mathrm{N}}$ is the rated insulation life in hours.

It can be observed from Equation (5) that the equivalent ageing of transformer is a function of hot-spot temperature, which can be determined as follows.

At each time interval $\Delta t_{\mathrm{n}}$ for the total studied time period $t$, the hot-spot temperature is assumed to consist of three components given by Equation (7) [23],

$$
\Theta_{H, n}=\Theta_{A, n}+\Delta \Theta_{T O, n}+\Delta \Theta_{H, n}
$$

where $\Theta_{A, n}, \Delta \Theta_{T O, n}$, and $\Delta \Theta_{H, n}$ are the ambient temperature, the top-oil rise over ambient temperature, and the winding hotspot rise over top-oil temperature, respectively, during the time interval $\Delta t_{\mathrm{n}}$ in degree Celsius. $\Theta_{A, n}$ can be determined by the ambient temperature profile over time. The top-oil temperature rise $\left(\Delta \Theta_{T O, n}\right)$ at a time after a step load can be expressed by 


$$
\begin{aligned}
\Delta \Theta_{T O, n}= & \Delta \Theta_{T O, R}\left\{\left[\left(\frac{K_{U, n}{ }^{2} R+1}{R+1}\right)^{p}-\left(\frac{K_{i, n}{ }^{2} R+1}{R+1}\right)^{p}\right]\right. \\
& \left.\times\left(1-\exp \left(\frac{R(R+1)^{p-1}\left(K_{U, n}{ }^{2}-K_{i, n}{ }^{2}\right) \Delta t}{\tau_{T O, R}\left[\left(K_{i, n}{ }^{2} R+1\right)^{p}-\left(K_{U, n}{ }^{2} R+1\right)^{p}\right]}\right)\right)\right\}
\end{aligned}
$$

where $\Delta \Theta_{T O, R}$ is the top oil rise over ambient temperature at rated load, $K_{U, n}$ is the ratio of the load at the end of any time interval of length $\Delta t$ to the rated load in per unit. $K_{i, n}$ is the ratio of the load at the beginning of any time interval of length $\Delta t$ to the rated load in per unit. $R$ stands for the ratio of load loss at rated load to no-load loss, and $p$ an empirically derived exponent to account for effects of change in resistance with change in load.

It can be observed from Equation (8) that top-oil temperature rise $\left(\Delta \Theta_{T O, n}\right)$ is a function of $K_{U, n}$, and $K_{i, n}$, due to the fact that $\Delta \Theta_{T O, R}, R$, and $p$ are constants for a specific transformer.

Similarly, the transformer winding hot-spot temperature rise is a function of $\Delta \Theta_{H, U}, \Delta \Theta_{H, i}$ and $\tau_{w}$, and can be expressed by

$$
\begin{aligned}
\Delta \Theta_{H, n} & =\left(\Delta \Theta_{H, U}-\Delta \Theta_{H, i}\right)\left(1-\exp \left(\frac{\Delta t}{\tau_{w}}\right)\right)+\Delta \Theta_{H, i} \\
& =\Delta \Theta_{H, R}\left\{\left(K_{U, n}{ }^{2 m}-K_{i, n}{ }^{2 m}\right) \times\left(1-\exp \left(\frac{\Delta t}{\tau_{w}}\right)\right)+K_{i, n}{ }^{2 m}\right\}
\end{aligned}
$$

where $\Delta \Theta_{H, U}$ and $\Delta \Theta_{H, i}$ are the ultimate and initial hot-spot temperature rise during the time interval $\Delta t_{\mathrm{n}}$ in degree Celsius, $\Delta \Theta_{H, R}$ is the rated value of hot-spot rise over top oil, $\tau_{w}$ is the winding time constant at hot spot location in hours, $m$ is the empirically derived exponent to account for changes in resistance and oil viscosity with changes in load.

It can be observed from the Equations (9) that the winding hot-spot rise over top-oil temperature is a function of $K_{U, n}$, and $K_{i, n}$, due to the fact that $\Delta \Theta_{H, R}$ and $m$ are constants for a specific transformer. It can therefore be concluded from Equations (7)-(9) that the hot-spot temperature, which determines the ageing of transformer, is a function of ambient temperature and load demand levels,

$$
\Theta_{H, n}=f\left(\Theta_{A, n}, K_{U}, K_{i}\right)
$$

where $f(\bullet)$ is a mathematical function of the hot spot temperature regarding ambient temperature and load levels. This function provides the mathematical basis to study the impact of FEVs charging loads on the thermal ageing of transformer.

\section{Methodology}

The method for the study is summarised in Figure 4. The first step is to read data for the study, including distribution network data, FEVs data and ambient temperature data. The distribution network data includes the load demand data and transformer thermal characteristics. FEVs data includes the FEVs charging start times, the individual FEVs charging characteristics, the initial state-of-charge (SOC) before recharging, and the FEVs charging modes. The FEVs loads can be stochastically formulated by accounting for the randomness in the FEVs data set. Next, the hot-spot temperature without FEVs charging loads is determined in order to calculate equivalent ageing factor at the base case. Subsequently, a penetration level of FEVs is selected to calculate the transformer load with inclusion of FEVs charging loads. The hot-spot temperature with FEVs charging loads can then be determined in order to calculate the equivalent ageing factor of transformers for each penetration level. By increasing the penetration level from $0 \%$ to $50 \%$, a curve will be generated showing the losses of transformer life over a period of time.

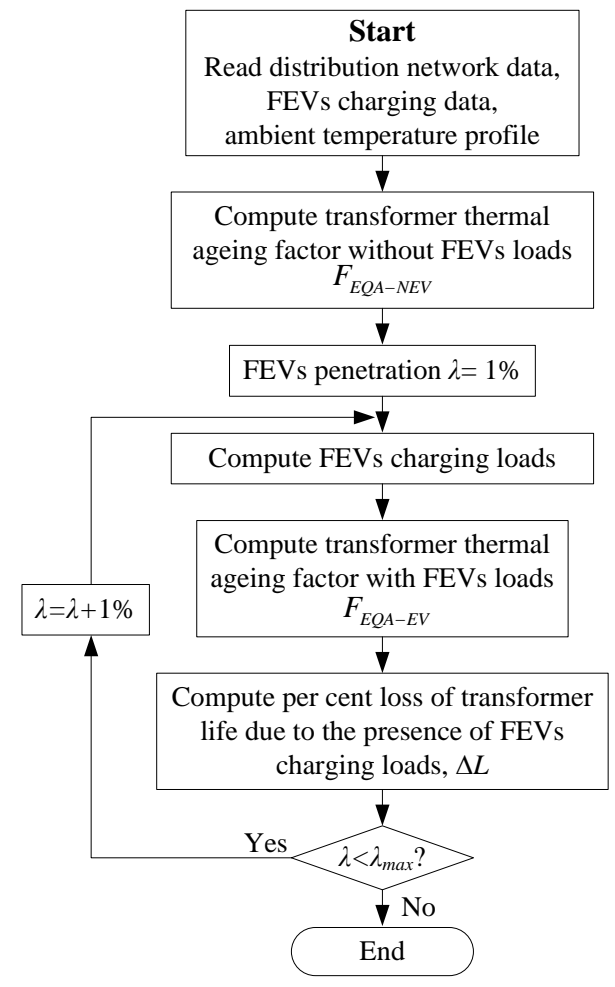

Fig. 4 Flow chart of the proposed method

Figure 5 shows the schematic to determine the FEVs charging loads, by taking into account the stochastic nature of FEV owners' charging behaviours, i.e., initial state-of-charge before recharging, start time of FEVs charging, and FEVs charging modes.

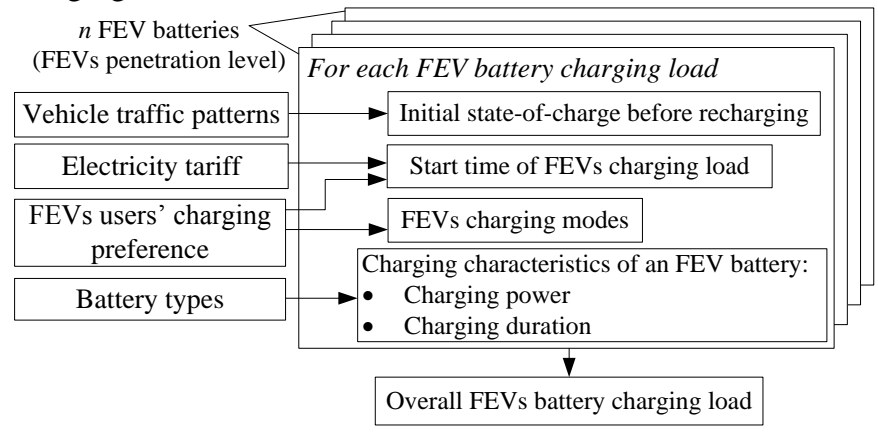

Fig. 5 A schematic to determine the FEVs charging loads

Detailed mathematical models to determine charging power demand of multiple EVs can be found in the work previously presented by the authors [6][24]. The models take into account the stochastic nature of EVs charging. 


\section{SIMULATION, RESULTS AND DISCUSSIONS}

\section{A. Studied system}

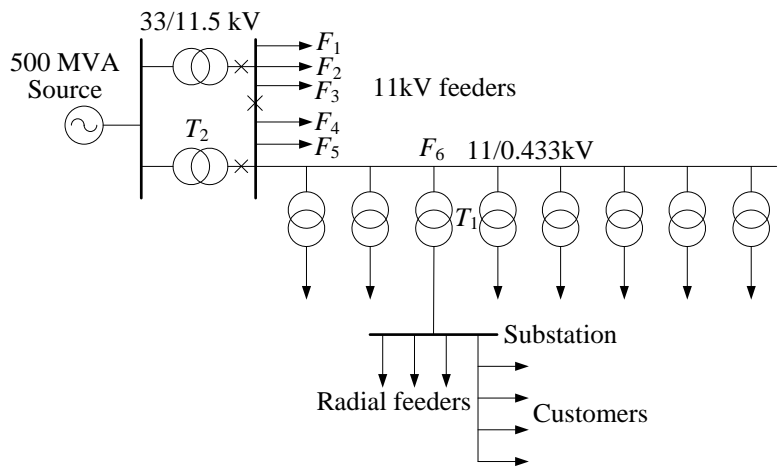

Figure 6 A 33/11/0.4kV residential distribution system used in the simulation

Figure 6 shows a generic urban distribution network, which was assessed by a number of Distribution Network Operators (DNOs) and considered as a representative of urban UK distribution networks [25].

The system consists of a 500MVA $33 \mathrm{kV}$ three-phase voltage source, two 33/11.5 kV 15 MVA YY0 transformers, an $11 \mathrm{kV}$ substation and six $11 \mathrm{kV}$ outgoing feeders $\left(F_{1}, F_{2}, F_{3}\right.$, $F_{4}, F_{5}$ and $F_{6}$ ). It is assumed that the first three feeders $F_{1}, F_{2}$, and $F_{3}$ are symmetric to the other three feeders $F_{4}, F_{5}$ and $F_{6}$. We assume $F_{4}$ supplies industrial loads, $F_{5}$ supplies commercial loads, while $F_{6}$ serves residential loads. Due to the unavailability of detailed data for the industrial feeder $F_{4}$, and the commercial feeder $F_{5}$, the loads at these two feeders are simplified as two lumped loads, while the residential feeder $F_{6}$ is modelled in detail. $F_{6}$ represents a 1.875 miles cable supplying eight $11 / 0.433 \mathrm{kV}$ distribution transformers and $400 \mathrm{~V}$ substations. Each $400 \mathrm{~V}$ substation supplies four outgoing feeders, each 0.1875 miles long, with a total of 384 domestic single-phase house loads, distributed equally among the feeder cables. Three of the $400 \mathrm{~V}$ feeders are represented as lumped load while only the fourth being represented in detail.

\section{B. Input data for the simulation}

A program is developed to assess the impact of FEVs charging loads on the thermal ageing of distribution transformer based on the methodology presented in this paper. The program calculates the hot-spot temperature and life consumption due to the FEVs charging loads on a half-hourly basis. The following data are used in the calculation.

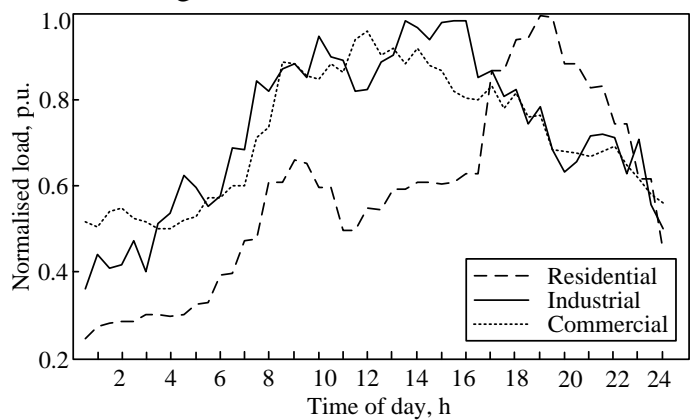

Fig. 7 Normalised load patterns of three load classes in winter in the UK

Half-hourly load demand data for the studied distribution system for a Calendar year Figure 7 shows the normalised load patterns of three load classes - residential, industrial and commercial in the UK [26].

It is assumed the load data given here is for winter (December to February) average data, a factor of 0.82 will be assigned for Spring average load, while 0.72 and 0.83 for summer (June to August) and autumn (September to November) average load, respectively, based on the statistical results from UK National Grid operational data [27].

Half-hourly ambient temperature data for a Calendar year Half-hourly ambient temperature data were derived from the UK Meteorological Office for central Scotland, UK for year 2010 [28].

FEVs penetration level FEV penetration level is defined as the ratio of FEVs to the total number of vehicles in the studied region to which the distribution system supplies power. As stated in Section 2, FEVs penetration level varies from $0 \%$ (base case) to $50 \%$.

FEVs customer charging behaviours, i.e., battery charging load profile, start time of FEVs charging, initial state-ofcharge before recharging and preference of charging modes. Lithium-ion battery charging profile is shown in Figure 3. Parameters of the charging curve for a $25-\mathrm{kWh}$ battery are shown in Table II.

TABLE II

PARAMETERS OF FEVS BATTERY CHARGING PROFILE

\begin{tabular}{cccc}
\hline \hline & Mode 1 & Mode 2 & Mode 3\&4 (fast charge) \\
\hline$P_{F E V}$ & $3.5 \mathrm{~kW}$ & $6.6 \mathrm{~kW}$ & $40 \mathrm{~kW}$ \\
$t_{1}$ & $6.3 \mathrm{~h}$ & $3.6 \mathrm{~h}$ & $0.5 \mathrm{~h}$ \\
$t_{2}$ & $8.0 \mathrm{~h}$ & $4.0 \mathrm{~h}$ & $0.75 \mathrm{~h}$ \\
\hline
\end{tabular}

Among the 28.4 million registered cars in the U.K. in 2010, about $96 \%$ were privately owned and $4 \%$ were companyowned [29]. Private cars are mainly used for commuting, shopping, visiting, escorting, and leisure, most of which are flexible in time. Company cars are used mainly for commuting and business, both of which are considered inflexible and employed more frequently than private cars. It is reasonable to assume that the proportion of ownership and usage of cars as outlined above also hold for FEVs.

Thermal characteristics of distribution transformers Input to the program which computes the losses of life due to FEV charging loads consists of the following:

a) repetitive $24 \mathrm{~h}$ load cycles,

b) $24 \mathrm{~h}$ ambient temperature, and

c) transformer thermal characteristics. Detailed characteristics are assumed according to [30] and [31] in Table III below.

TABLE III

THERMAL CHARACTERISTICS OF POWER TRANSFORMERS

\begin{tabular}{ccc}
\hline \hline & $33 / 11.5 \mathrm{kV}$ & $11 / 0.433 \mathrm{kV}$ \\
Transformer & Transformer \\
\hline$\Delta \Theta_{T O-R}$ & $65.0^{\circ} \mathrm{C}$ & $55.0^{\circ} \mathrm{C}$ \\
$\Delta \Theta_{H-R}$ & $30.0^{\circ} \mathrm{C}$ & $20.3^{\circ} \mathrm{C}$ \\
$R$ & 3.2 & 8 \\
$\tau_{R}$ & $3.5 \mathrm{~h}$ & $3.0 \mathrm{~h}$ \\
$p$ & 0.9 & 0.9 \\
$m$ & 0.8 & 0.8 \\
$\tau_{w}$ & $4.8 \mathrm{mins}$ & $10 \mathrm{mins}$ \\
$L_{N}$ & $180,000 \mathrm{hrs}$ & $180,000 \mathrm{hrs}$ \\
\hline \hline
\end{tabular}




\section{Simulation results}

- Scenario A. Uncontrolled domestic charging

In this scenario, it is assumed that there is no incentive for FEV owners to avoid peak time charging, i.e., a fixed electricity rate is employed. In this 'worst case' scenario, half of FEVs (FEVs are assumed to charge every two days on average) at nearly the same time (at 19.00). It is assumed in this scenario that half the FEVs to be charged will employ Mode 1 for charging; while the half employs Mode 2.

Figures 8 and 9 show the power load of the $11 / 0.433 \mathrm{kV}$ transformer (Transformer $\mathrm{T} 1$ ) and the $33 / 11.5 \mathrm{kV}$ transformer (Transformer T2), with inclusion of FEV charging load over 24 hours for Scenario A.

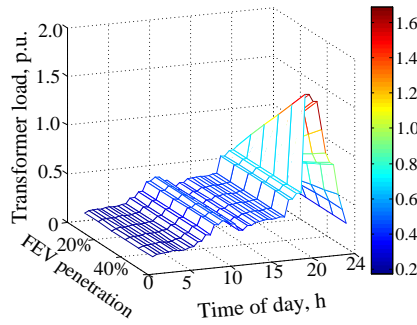

(a) summer weekday

(b) winter weekday
Fig. 8 Power load of transformer 1 (T1) for Scenario A

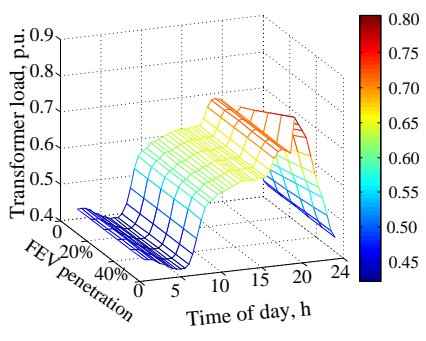

(a) summer weekday
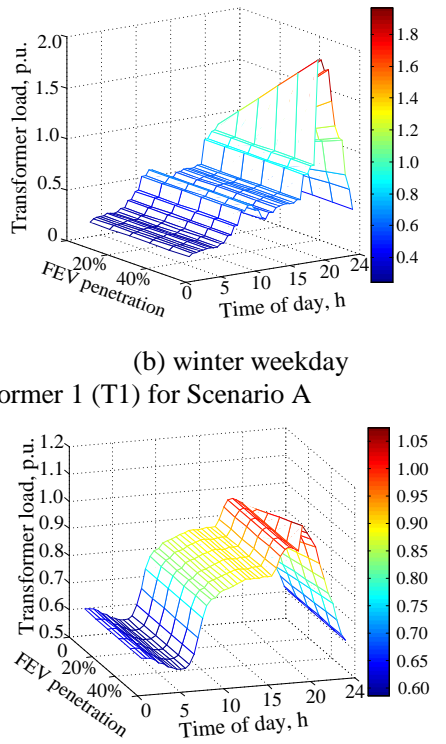

(b) winter weekday
Fig. 9 Power load of transformer 2 (T2) for Scenario A

It can be observed from Figure 8 that in the 'worst case' charging scenario FEV charging load imposes a significant increase on the peak load, due to the uncontrolled charging load for both summer and winter weekdays. Results show that FEVs result in a higher peak load in a typical winter weekday than that of a typical day in summer, due to the larger portion of heating load in winter. Such a significant increase in peak electricity demand will significantly impact on local distribution systems with respect to capacity limit and thermal ageing. This suggests the need to devise and provide proper incentives to achieve distributed charging load during the offpeak hours, even at low levels of FEV penetration. Results shown in Figure 9 indicate a lower percentage of peak load increase imposed by FEVs charging load, due to the larger base load of the transformer.

Table IV shows the loss of life (LOL) of the $11 / 0.433 \mathrm{kV}$ transformer (Transformer T1) and the $33 / 11.5 \mathrm{kV}$ transformer (Transformer T2), respectively under uncontrolled domestic charging for typical weekday load profiles in summer and winter respectively. $\Delta L$ denotes the LOL as a result of extra FEVs charging load imposed on the transformers for various penetration levels ranging from $0 \%$ to $50 \%$.
TABLE IV

LOL OF TRANSFORMERS DUE TO FEVS CHARGING LOAD FOR SCENARIO A

\begin{tabular}{ccccc}
\hline \hline & \multicolumn{2}{c}{ Summer Weekday } & \multicolumn{2}{c}{ Winter Weekday } \\
\hline & $\mathrm{T} 1$ & $\mathrm{~T} 2$ & $\mathrm{~T} 1$ & $\mathrm{~T} 2$ \\
\hline $\begin{array}{c}\text { FEV } \\
\text { penetration }\end{array}$ & $\Delta L(\%)$ & $\Delta L(\%)$ & $\Delta L(\%)$ & $\Delta L(\%)$ \\
\hline $0 \%$ & 0.0000 & 0.0000 & 0.0000 & 0.0000 \\
$10 \%$ & 0.0057 & 0.0009 & 0.0041 & 0.0007 \\
$20 \%$ & 0.0112 & 0.0043 & 0.0082 & 0.0038 \\
$30 \%$ & 0.0141 & 0.0080 & 0.0123 & 0.0069 \\
$40 \%$ & 0.0208 & 0.0124 & 0.0164 & 0.0110 \\
$50 \%$ & 0.0245 & 0.0152 & 0.0205 & 0.0131 \\
\hline \hline
\end{tabular}

In Table IV, the first result that claims attention is the trend of LOL which are monotonically increasing. This means that, as expected, the LOL of the transformer generally increases as the penetration level of the FEVs increases. This trend has appeared in all of the scenarios. It can be observed that with a $50 \%$ penetration of FEVs in summer, the daily LOL of T1 can reach $0.0245 \%$ due to the FEVs charging load, which translates to 44.1 hours. The uncontrolled increase in LOL and ageing acceleration will add to the maintenance requirements and will likely lead to early replacement of transformers. Although load levels in winter is generally greater than those of summer, as can be seen from the table, the LOL of the analyzed transformers in summer is higher than that in winter, due to the much higher ambient temperature in summer. Results also show that due to the larger capacity, the loading relative of its capacity of the $33 / 11.5 \mathrm{kV}$ transformer $\mathrm{T} 2$ is much lower than that of $\mathrm{T} 1$. This consequently results in a much lower value of LOL.

- Scenario B. Uncontrolled domestic off-peak charging

In this scenario, time-of-use (TOU) electricity rate structure is adopted to reflect the existence and possible introduction of new policies to encourage FEV owners to recharge vehicles during the off-peak time. In this paper, the peak load time is defined as from 7.00 am to $8.59 \mathrm{pm}$, while off-peak load time is defined as from $9.00 \mathrm{pm}$ to $6.59 \mathrm{am}$.

Figures 10 and 11 show the load of $\mathrm{T} 1$ and $\mathrm{T} 2$, with inclusion of FEV charging over 24 hours for Scenario B.

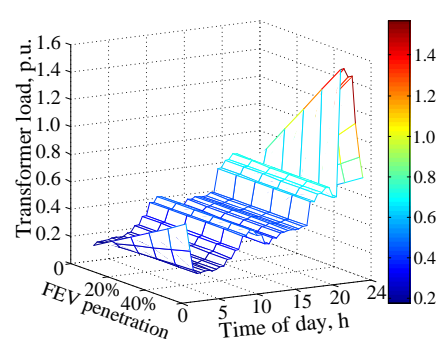

(a) summer weekday

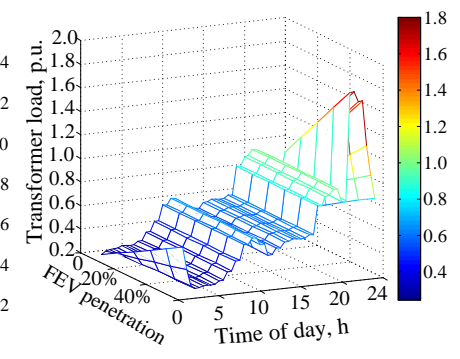

(b) winter weekday

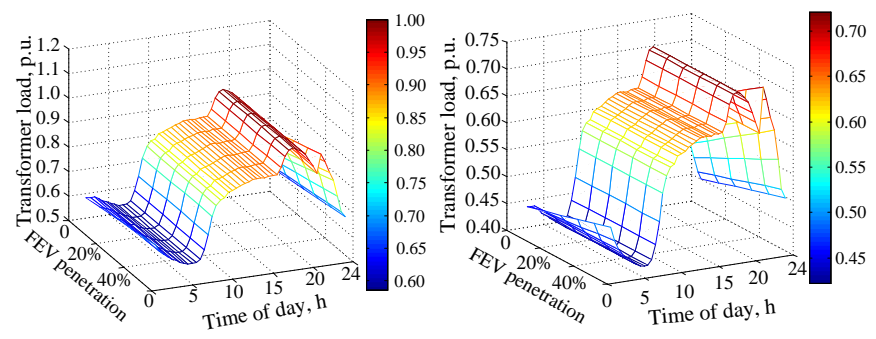

(a) summer weekday

(b) winter weekday 
Fig. 11 Power load of transformer 2 (T2) for Scenario B

It can be seen from Figures 10 and 11 that under the uncontrolled off-peak domestic charging scenario, there is a significant increase of load demand between $9.00 \mathrm{pm}$ and midnight consequently introduces a new peak to the load profile. This is because that although the time-of-use electricity tariff can shift most of the FEV charging loads to off-peak load time in this scenario, the assumed flat off-peak electricity price is unable to encourage FEV users to charge their vehicles at a later time near midnight. The rest of charging loads from midnight to early morning are comfortably absorbed by the whole system without an increase to peak demand.

Table V shows the loss of life of the two transformers under uncontrolled domestic off-peak charging for a typical weekday in summer and winter respectively.

TABLE V

LOL OF TRANSFORMERS DUE TO FEVS CHARGING LOAD FOR SCENARIO B

\begin{tabular}{ccccc}
\hline \hline & \multicolumn{2}{c}{ Summer } & \multicolumn{2}{c}{ Winter } \\
\hline $\begin{array}{c}\text { FEV } \\
\text { penetration }\end{array}$ & $\Delta L(\%)$ & $\Delta L(\%)$ & $\Delta L(\%)$ & $\Delta L(\%)$ \\
\hline $0 \%$ & 0.0000 & 0.0000 & 0.0000 & 0.0000 \\
$10 \%$ & 0.0022 & 0.0007 & 0.0016 & 0.0006 \\
$20 \%$ & 0.0063 & 0.0035 & 0.0057 & 0.0031 \\
$30 \%$ & 0.0116 & 0.0064 & 0.0088 & 0.0059 \\
$40 \%$ & 0.0167 & 0.0099 & 0.0129 & 0.0092 \\
$50 \%$ & 0.0211 & 0.0142 & 0.0170 & 0.0132 \\
\hline \hline
\end{tabular}

Results in Table $\mathrm{V}$ show that while the given coordination approach is beneficial in overall system load levelling and peak shaving, high FEV penetrations may still result in significant increases in individual transformer loads that may exceed their ratings. Therefore, the night time loading of FEV in charging coordination may not be so favorable if high FEV penetrations prevent sufficient transformer cooling overnight. This may in the long run impact transformer service life.

- Scenario C. Smart domestic charging

In this scenario the real-time electricity rate is employed to determine the most economic start time of FEV battery charging. It was envisaged that there will be an active management system based on two hierarchical control structures, one headed by an Aggregator and other by the system operators (DNO). Further it was assumed that FEV charging is controlled according to the Aggregator's market negotiations or according to the need of the system operators. Compared with previous charging, "smart" charging represents a shift of FEV charging load from the system peak demand time to the valley hours.

Figures 12 and 13 show the power load of $\mathrm{T} 1$ and T2, with inclusion of FEV charging load over 24 hours for Scenario C.

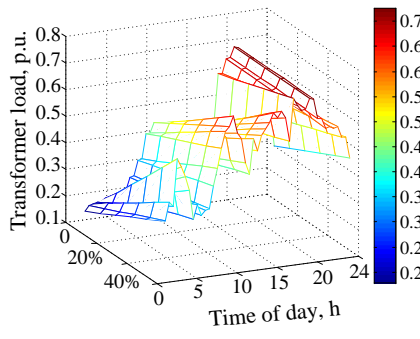

(a) summer weekday

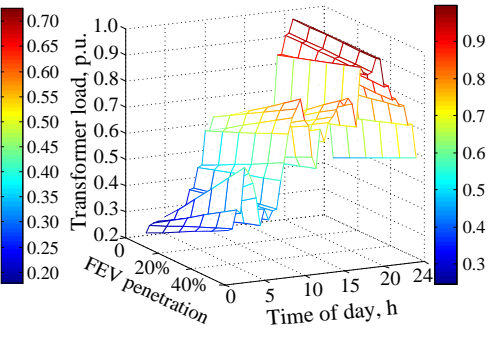

(b) winter weekday
Fig. 12 Power load of transformer 1 (T1) for Scenario C

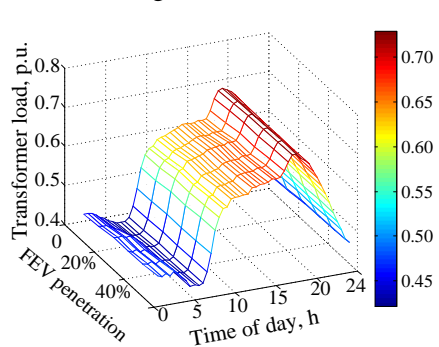

(a) summer weekday

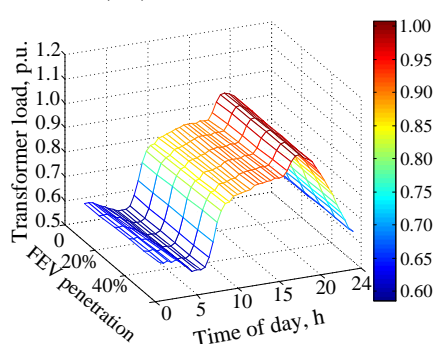

(b) winter weekday
Fig. 13 Power load of transformer 2 (T2) for Scenario C

The charging load at each time instant is the result of the optimal distribution of start time. Results in Figures 12 and 13 show that at $1.00 \mathrm{am}$, the proportion of FEVs starting charging has its largest value. From the electric utility operation aspect, the potential of FEVs smart charging to fill in the valley in the load curve will result in more electricity sales for the same system capacity.

Table VI shows the LOL of the two transformers under smart domestic charging for a typical weekday in summer and winter, respectively.

TABLE VI

LOL OF TRANSFORMERS DUE TO FEVS CHARGING LOAD FOR SCENARIO C

\begin{tabular}{ccccc}
\hline \hline & \multicolumn{2}{c}{ Summer } & \multicolumn{2}{c}{ Winter } \\
\hline $\begin{array}{c}\text { FEV } \\
\text { penetration }\end{array}$ & $\Delta L(\%)$ & $\Delta L(\%)$ & $\Delta L(\%)$ & $\Delta L(\%)$ \\
\hline $0 \%$ & 0.0000 & 0.0000 & 0.0000 & 0.0000 \\
$10 \%$ & 0.0015 & 0.0006 & 0.0010 & 0.0005 \\
$20 \%$ & 0.0049 & 0.0029 & 0.0031 & 0.0025 \\
$30 \%$ & 0.0078 & 0.0056 & 0.0059 & 0.0049 \\
$40 \%$ & 0.0099 & 0.0079 & 0.0078 & 0.0068 \\
$50 \%$ & 0.0126 & 0.0107 & 0.0110 & 0.0102 \\
\hline \hline
\end{tabular}

From Table VI, it is observed that there is a reduction in the transformers' LOL compared to the previous two charging scenarios, due to the coordinated charging activities. Under this scenario, the transformer LOL can reach even to approximately half of the uncontrolled domestic charging scenario. However, as revealed by Table VI, with more penetration of FEVs, there is also considerable increase in the LOL. This can be inferred by comparing the contents of various rows in Table VI.

- Scenario D. Uncontrolled public charging

In this scenario, among FEVs, a proportion of $50 \%$ will be recharged at the owners' workplaces in industrial areas, while $30 \%$ is allowed to recharge at the owners' workplaces in commercial areas, the rest $20 \%$ of FEVs will be charged at home.

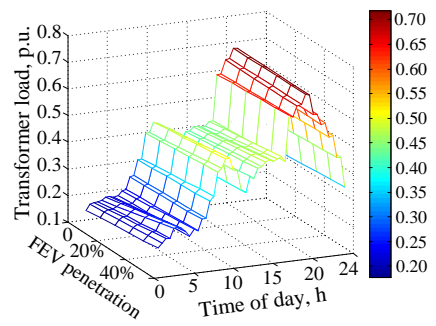

(a) summer weekday

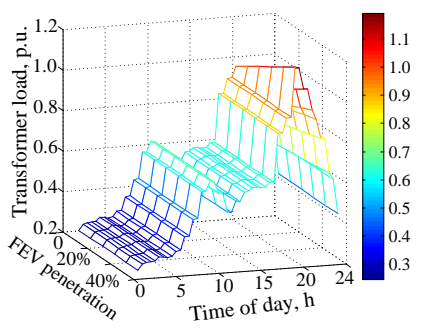

(b) winter weekday 
Fig. 14 Power load of transformer 1 (T1) for Scenario D

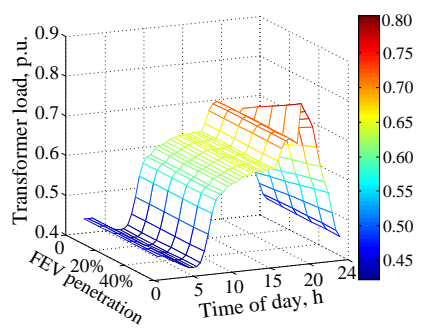

(a) summer weekday

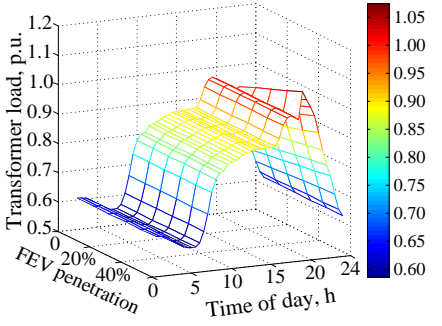

(b) winter weekday
Fig. 15 Power load of transformer 2 (T2) for Scenario D

Figures 14 and 15 show the power load of transformers T1 and T2, with inclusion of FEV charging load over 24 hours for Scenario D.

Figure 14 shows the load profile of T1 under the scenario of uncontrolled public charging. It can be observed that due to the shift of FEVs charging loads to industrial and commercial areas, the left charging loads in residential areas does not form significant increase in load demand. However, the shift of FEV charging loads to industrial and commercial areas may cause new peaks of load demand for these two areas, due to the nature of these two loads, shown in Figure 15. This means that the existing industrial and commercial loads may not absorb FEV charging load without exceeding the natural peak load if all FEVs start charging at the same time.

Table VII shows the LOL of T1 and T2, under uncontrolled public charging for typical weekday load profiles in summer and winter respectively. As can be seen from Table VII, the seasonal LOL of T1 is reduced by shifting a large percentage of charging loads to commercial and industrial areas. However, results in the table show that transformer T2 suffers from being overloaded due to the uncoordinated charging in industrial and commercial areas.

TABLE VII

LOL TRANSFORMERS DUE TO FEVS CHARGING LOAD FOR SCENARIO D

\begin{tabular}{ccccc}
\hline \hline & \multicolumn{2}{c}{ Summer } & \multicolumn{2}{c}{ Winter } \\
\hline $\begin{array}{c}\text { Transformer } \\
\text { No.1 }\end{array}$ & $\begin{array}{c}\text { Transformer } \\
\text { No.2 }\end{array}$ & $\begin{array}{c}\text { Transformer } \\
\text { No.1 }\end{array}$ & $\begin{array}{c}\text { Transformer } \\
\text { No.2 }\end{array}$ \\
\hline FEV & $\Delta L(\%)$ & $\Delta L(\%)$ & $\Delta L(\%)$ & $\Delta L(\%)$ \\
\hline $0 \%$ & 0.0000 & 0.0000 & 0.0000 & 0.0000 \\
$10 \%$ & 0.0016 & 0.0021 & 0.0008 & 0.0012 \\
$20 \%$ & 0.0033 & 0.0043 & 0.0016 & 0.0039 \\
$30 \%$ & 0.0045 & 0.0082 & 0.0024 & 0.0071 \\
$40 \%$ & 0.0060 & 0.0117 & 0.0033 & 0.0104 \\
$50 \%$ & 0.0078 & 0.0155 & 0.0041 & 0.0133 \\
\hline \hline
\end{tabular}

\section{Discussions}

This paper is focused on developing a methodology to model FEV charging load and the resulting impact on the thermal ageing of transformers. It has not taken into account the heating due to current harmonic content, high-frequency eddy-current loss in the copper or aluminium of the windings. This may result in an underestimation of the LOL due to FEV charging as harmonics of non-sinusoidal charging current generated by the electronic devices in the charger may cause temperature rise in transformers, thus worsens the LOL. However, it is assumed in this paper that a proper harmonics filter is installed at the charger side to prevent harmonic current from flowing into transformers.

Another simplification was also made in this paper that only charging scenarios during weekdays are considered. It is expected that the seasonal LOL of the analysed transformers may be lower in weekends because of the distinct behaviour of customer loads in these days. In fact, it is less probable for people to be present at home or work over weekends. As a result, their power consumption may be less than that during weekdays. Thus, the transformer would suffer lower loss of its useful life in weekends than weekdays.

\section{CONCLUSIONS}

This paper presents a detailed methodology to quantity the increase in power transformers' loss of life as a result of the charging loads introduced to distribution systems by FEVs. Detailed mathematical models which take into account the stochastic nature of FEVs charging are developed and applied into the detailed transformer thermal model, which takes into consideration of all the major factors that determine transformer loss of life. Four FEV charging scenarios, named uncontrolled domestic charging, off-peak domestic charging, smart charging and uncontrolled public charging were simulated under various FEV penetration levels to investigate the effect of FEV charging load on the additional life consumption of power transformers. Through simulations and analysis, the paper comes into the following conclusions,

- The loss of life of a transformer depends on the effective values of load and temperature in each time instant. Results showed that high penetration of FEVs can have significant impact on power transformers' life particularly in the case with poor coordination of charging times. Conversely, low penetration of FEVs is not detrimental to the transformer life.

- It is highlighted in the paper that although overnight offpeak charging alleviates the loading of transformers, the nighttime charging may not be so favorable if high FEV penetrations prevent sufficient transformer cooling overnight. This may in the long run impact transformer service life.

- By analysing the results, it was concluded that the smart charging scenario generally shows the best outcome from the loss of life reduction perspective. Meanwhile, public charging which shifts a large percentage of charging load to commercial and industrial areas can significantly alleviate the residential transformer loading thus imposing little impact on the LOL. Results also show that the LOL of example transformers varies dramatically over various seasons of the year under the same FEV loading conditions. The values of the LOL due to FEV charging in the summer tend to be higher than the winter LOL rate.

\section{REFERENCES}

[1] J.T. Salihi, "Energy Requirements for Electric Cars and Their Impact on Electric Generation and Distribution Systems," IEEE Trans. Industry Applications, vol. 1A-9, no. 5, Sept/Oct, 1973. 
[2] S. Rahman, G.B. Shrestha, "An investigation into the impact of electric vehicle load on the electric utility distribution system," IEEE Trans. Power Delivery, vol. 8, no. 2, April 1993, pp.591-597.

[3] IET Transport desk, "UK grid capacity 'sufficient' for electric vehicles," Published on 1 May 2009.

[4] R. Webster, "Can the electricity distribution network cope with an influx of electric vehicles?" Journal of Power Sources, vol.80, no.1-2, July 1999 , pp.217-225.

[5] C. Walton, R. Mackinlay, "PD Monitoring-A Critical Tool For Condition-Based Assessments," Transmission \& Distribution World, pp.38-46, 2003.

[6] K. Qian, C. Zhou, M. Allan, and Y. Yuan. "Modelling of Load Demand due to EV Battery Charging in Distribution Systems," IEEE Trans. Power Systems, 2010.

[7] P.T. Staats, W.M. Grady, A. Arapostathis, R.S. Thallam, "A statistical method for predicting the net harmonic currents generated by a concentration of electric vehicle battery chargers," IEEE Trans. Power Delivery, vol.12, no.3, pp.1258-1266, Jul 1997.

[8] P.T. Staats, W.M. Grady, A. Arapostathis, R.S. Thallam, “A statistical analysis of the effect of electric vehicle battery charging on distribution system harmonic voltages,", IEEE Trans. Power Delivery, vol.13, no.2, pp.640-646, Apr 1998.

[9] J. A. Orr, A. E. Emanuel, D. J. Pileggi, "Current Harmonics, Voltage Distortion, and Powers Associated with Electric Vehicle Battery Chargers Distributed on the Residential Power System," IEEE Trans. Industry Applications, vol.IA-20, no.4, pp.727-734, July 1984.

[10] J. C. Gómez, M. M. Morcos, "Impact of EV battery chargers on the power quality of distribution systems," IEEE Trans. Power Delivery, vol. 18 , no. 3, pp. 975-981, July 2003.

[11] Scottish and Southern Energy plc, Final report for the year to 31 March 2011, 20 May 2011.

[12] Department for Transport, Vehicle licensing statistics, available on website http://www.dft.gov.uk/, access date: 1st March, 2011.

[13] National Statistics, Department for Transport. "Transport statistics bulletin-national travel survey: 2008", $9^{\text {th }}$ April 2009.

[14] US EPA, Fuel Economy and Environmental Comparisons, access date: $1^{\text {st }}$ March 2011.

[15] National Statistics, Department for Transport, "Travel to work-personal travel factsheet", July 2007.

[16] Frank Lambert. 'Secondary distribution impacts of residential electric vehicle charging,' California Energy Commission, May 2000.

[17] J.H. Yuan. 'Customer Response Under Time-of-Use Electricity Pricing Policy Based on Multi-Agent System Simulation,' 2006 IEEE PES Power Systems Conference and Exposition, 2006. PSCE '06.Oct. 29 2006-Nov. 2006, pp.814 - 818.

[18] J.Y. Choi, S.H. Rim, J.K. Park, "Optimal real time pricing of real and reactive powers," IEEE Trans. Power Systems, vol. 13, no. 4, pp.1226 1231, Nov. 1998.

[19] APX Power UK Daily Settlement Prices, available on: http://www.ukpx.co.uk, date of access: Jan. 2008.

[20] IEC, "IEC61851 Part 1: Charging of electric vehicles up to 250A a.c. and 400A d.c.," First Edition 2003-04.

[21] G. B. Rauch, G. Johnson, P. Johnson, A. Stamm, S. Tomita, J. Swanson, "A comparison of international residential grounding practices and associated magnetic fields." IEEE Trans. on Power Delivery, vol. 7, no. 2, April 1992.

[22] G. T. Heydt, "The impact of electric vehicle deployment on load management strategies," IEEE Trans. Power Apparatus and Systems, vol.PAS-102, no.5, pp.1253-1259, May 1983.

[23] IEEE C57.91-1995, IEEE Guide for Loading Mineral-Oil-Immersed Transformer, 14th June, 1995.

[24] P. Zhang, K. Qian, C. Zhou, B.G Stewart, D.M Hepburn, "A Methodology for Optimization of Power Systems Demand Due to Electric Vehicle Charging Load," IEEE Trans. Power Systems, vol. 27, no. 3, pp. 1628-1636, August 2012.

[25] Steve Ingram, Sarah Probert, Katherine Jackson, "The impact of small scale embedded generation on the operating parameters of distribution networks," DTI New and Renewable Energy Programme, report number: K/EL/00303/04/01, 2003.

[26] DTI Centre for Distributed Generation and Sustainable Electrical Energy, United Kingdom Generic Distribution System (UKGDS) Phase One, March 2006.
[27] National Grid. Operational Data - metered half-hourly electricity demands, available on

http://www.nationalgrid.com/uk/Electricity/Data/, access date: 1st March 2011.

[28] Met Office, http://www.metoffice.gov.uk/, access date: 3rd March 2011.

[29] National Statistics, Department for Transport, Vehicle Licensing Statistics: 2010, April, 2011.

[30] ANSI/IEEE C57.91-1981, "Guide for loading mineral-oil-immersed overhead and pad-mounted distribution transformers - rated 500kVA and less with $65^{\circ} \mathrm{C}$ or $55^{\circ} \mathrm{C}$ average winding rise," American National Standards Institute, July 1981.

[31] M. Kuss, T. Markel, W. Kramer, "Application of distribution transformer thermal life models to electrified vehicle charging loads using Monte-Carlo method," in the proceeding of $25^{\text {th }}$ World Battery, hybrid and fuel cell electric vehicle symposium \& exhibition, November 2010.

\section{BIOGRAPHIES}

Kejun Qian received his BSc in 2004 in Electrical Engineering from Hohai University, China. Having received his $\mathrm{PhD}$ degree in Electrical Engineering from Glasgow Caledonian University (GCU), UK in 2010, he joined the School of Engineering and Computing at GCU in 2010 and worked as a PostDoc Research Fellow. In 2011, he joined the Department of Electrical and Electronic Engineering in Xi'an Jiaotong Liverpool University as a Lecturer. Currently, he is working as a Senior Engineer for the State Grid Corporation of China. His research areas include electric vehicles, smart grid and renewable energy systems.

Jiaqing Zhao received his BSc in 2003 in Electrical Engineering from Hefei University of Technology, China. He is working as a Senior Engineer of the Power Dispatching and Control Centre of Suzhou Power Supply Company, State Grid Corporation of China. His research interests include power system analysis and control.

Chengke Zhou (M'07, SM'13) received his BSc and MSc in 1983 and 1986 respectively from Huazhong University of Science and Technology, China. Having received his PhD degree from The University of Manchester, UK in 1994, he joined the School of Engineering and Computing at Glasgow Caledonian University (GCU) in 1994 and worked as Post-Doc Research Fellow, Lecturer and Senior Lecturer until August 2006 when he joined Heriot-Watt University as a Reader. In June 2007 he returned to GCU as a Professor. He has 30 years research experience in power systems and partial discharge based HV plant condition monitoring and has acted as consultant to EDF Energy, Scottish Power plc, British Energy and NEC Scotland. He has so far published over 100 papers.

Yue Yuan received the BSc and MSc degrees in Electrical Engineering from Xi'an Jiaotong University, Xi'an, China, in 1987 and 1990, respectively. He received the Ph.D. degree from Hiroshima University, Japan, in 2002. He joined the faculty of Xi'an Jiaotong University, China, in 1990. He is with Hohai University, Nanjing, China, as a professor since 2003. Presently, he is Dean of the College of Energy and Electrical Engineering, Hohai University. His research interests include power system operation and optimization, renewable energy, and smart grids. 